others would certainly point to a myocardial element, although we would also question whether left ventricular dilatation and pulmonary oedema might, in addition to acute cardiac failure, reflect fluid overload. ${ }^{5}$ The pulmonary wedge pressures were not stated.

\section{ElizABETh Fagan} A FORBES

Liver Unit,

ROGER WILLIAMS

King's College Hospital,

London SE5 8RX

1 Weston MJ, Talbot IC, Howorth PJN, et al. Frequency of arrhythmias and other cardiac abnormalities in fulminant arrhythmias and other cardiac abnormalites
hepatic failure. Br Heart $f$ 1976;38:1179-88.

2 Trewby PN, Williams R. Pathophysiology of hypotension in patients with fulminant hepatic failure. Gut 1977;18:1021-6. 3 Ede R, Williams R. Hepatic encephalopathy and cerebral edema. Semin Liver Dis 1986;6:107-18.

4 O'Grady JG, Gimson AES, O'Brien CJ, et al. Controlled trials of charcoal hemoperfusion and prognostic factors in fulminan hepatic failure. Gastroenterology (in press).

5 Bihari DJ, Gimson AES, Williams R. Cardiovascular, pulmonary and renal complications of fulminant hepatic failure. Semin Liver Dis 1986;6:119-28.

AUTHORS' REPLY,-Dr Fagan and her colleagues agree with the basic issue that toxic myocarditis is seen in some cases of paracetamol poisoning. They also acknowledge that left ventricular dilatation and pulmonary oedema seen at necropsy reflect acute cardiac failure. We would like to assure them that our patient received the standard treatment for cerebral oedema, including intravenous mannitol and hyperventilation, but without success. Fluid intake exceeded output by less than 1 litre in 21 hours, and, allowing for invisible water loss and a mild degree of dehydration, the total fluid intake was appropriate. Fluid overload was therefore unlikely.

It is true that some of the features they refer to can be attributed to uncontrolled cerebral oedema, but cerebral oedema can itself be a consequence of hypoxia complicating arrhythmia and hypotension. Furthermore, they use the term "brain stem coning" rather loosely and suggest that the mere presence of cerebral odema without tonsillar compression is equivalent to brain stem coning. This statement is a departure from accepted teaching in pathology. It raises another important question relating to the grade of cerebral oedema which they consider equivalent to brain stem coning. Such a flexible interpretation lacks precision and must therefore be rejected.

Nevertheless, some deaths from paracetamol poisoning occur without evidence of hepatic necrosis at necropsy. In a study cited by Meredith et al 61 out of 65 patients who died outside hospital showed no hepatic necrosis at necropsy. ${ }^{1}$ Such an alarmingly high figure should not be attributed to factors like the concomitant intake of drugs or alcohol without considering other possibilities including that of paracetamol induced arrhythmia. ${ }^{2}$ In a report on the failure of naloxone to reverse the cardiotoxic effect of dextropropoxyphene, a component of Distalgesic, the authors recorded bizarre complexes of hypotension. ${ }^{3}$ Their patient later arrested and was successfully resuscitated. Unfortunately, they failed to recognise that paracetamol might have been the cause. An interesting feature which this patient shared with ours was the poor clearance of paracetamol from the plasma. We believe there is enough evidence in the case we reported to suggest myocardial toxicity from paracetamol.

RIADH A WAKEEL

HUW T DAVIES JOHN D WILliamS

Medical Unit,

Orpington Hospital

Orpington, Kent BR6 9JU
Meredith TJ, Prescott LF, Vale JA. Why do patients still die from paracetamol poisoning? BrMed f 1986;293:345-6.

Will EJ, Tomkins AM. Acute myocardial necrosis in paracetam poisoning. BrMed f 1971;iv:430-1.

3 Barraclough CJ, Lowe RA. Failure of naloxone to reverse the cardiotoxicity of Distalgesic overdose. Postgrad Med $\mathscr{J}$ 1982;58:667-8.

\section{Charging patients for eye tests}

SIR,-While there is much in the government's white paper Promoting Better Health which could improve the provision of primary health care there are potentially serious implications in the introduction of charges to patients for eye tests.

Diabetes mellitus is the leading cause of blindness in people of working age in the United Kingdom. ${ }^{1}$ Treatment with photocoagulation of both proliferative retinopathy and maculopathy can prevent some $60 \%$ of blindness, ${ }^{23}$ but the changes must be detected early. Regular funduscopy is performed on patients attending diabetic clinics, but less than half of all known diabetic patients attend clinics, the remainder obtaining all supplies from their general practitioners. ${ }^{4-6}$ These patients are much less likely to have regular funduscopy. ${ }^{4}$ Moreover, on a general practitioner's list of 2000 patients there will be 20 diabetics, so that even if that general practitioner performs annual dilated funduscopy on all nonclinic attenders this will comprise only 10 examinations a year. As the prevalence of retinopathy is around $30 \%$ and of sight threatening retinopathy $10 \%{ }^{7}$ the general practitioner will be extremely unlikely to obtain the experience necessary to provide an effective role in screening.

Two studies have shown that optometrists detect serious retinopathy with high sensitivity. ${ }^{89}$ These results and the anxiety expressed by general practitioners about their ability to detect retinopathy have encouraged many to work with local optometrists in providing comprehensive screening for their diabetic patients.

In this district we are piloting a study, funded by the British Diabetic Association, to evaluate the benefits of a computerised register of diabetic patients. ${ }^{10}$ The computer will be used to prompt general practitioners and patients about regular examinations and blood tests. Because of the anxieties of the participating general practitioners over funduscopy we have agreed with loca optometrists that they will screen for retinopathy by funduscopy after the instillation of mydriatic drops.

In a district with a population of 200000 half of the 2000 known diabetics would not be attending hospital. The incidence of sight threatening retinopathy is $1 \cdot 2 \%$ a year, ${ }^{7}$ which corresponds to 12 cases a year in these non-hospital attenders, and photocoagulation could prevent blindness in seven of these patients. Using Foulds's figure of $£ 3500$ as the annual cost to the state of supporting a blind person $^{7}$ it is possible to perform a simple costbenefit analysis of retinal screening by optometrist under the present system of reimbursing $£ 9.30$ for the eye test: costs of screening 1000 diabetic patients_- $£ 9300$; benefits of preventing seven cases of blindness- $£ 24500$

At a time when an effective treatment has been introduced for treating retinopathy and when the DHSS itself is looking at ways of screening effectively for diabetic retinopathy, ${ }^{\text {" no major }}$ hurdle should be introduced to the screening role of the optometrist. The introduction of an exemption category so that diabetic patients would continue to obtain free eye tests would help to answer this problem, but other difficulties would remain. Some $8 \%$ of diabetic patients have retinopathy at diagnosis, ${ }^{12}$ and changes in refraction produced by high blood glucose concentrations are responsible for many patients with undiagnosed diabetes attending an optometrist. The fact that optometrists are often responsible for diagnosis in these patients means that they have an important role in screening for disease as well as detecting complications. It is therefore important that the free eye test should remain.

JOHN S YUDKIN

Academic Unit of Diabetes and Endocrinology,

Whittington Hospital,

London N195NF

1 Sorsby A. The incidence and causes of blindness in England and Wales 1963-1968. London: HMSO, 1972. (DHSS Reports on Public Health and Medical Subjects No 128.)

2 British Multicentre Study Group. Photocoagulation for diabetic maculopathy. A randomised controlled study using the xenon-arc. Diabetes 1983;32:1010-6.

3 British Multicentre Study Group. Photocoagulation for proliferative diabetic retinopathy: a randomised controlled trial liferative diabetic retinopathy: a randomised controlled
using the xenon-arc laser. Diabetologia 1984;26:109-15.

4 Yudkin JS, Boucher BJ, Schopflin KE, et al. The quality of Yudkin JS, Boucher BJ, Schopflin KE, et al. The quality of
diabetic care in a London health district. $\mathcal{f}$ Epidemiol diabetic care in a London health
Community Health 1980;34:277-80.

5 Fleming PC. What is happening to our diabetic patients? An audit of care in general practice. Practical Diabetes 1985;2: 26-9.

6 Doney BJ. An audit of care of diabetics in group practice. $f R$ Coll Gen Pract 1976;26:734-42.

7 Foulds WS, McCuish A, Barrie T, et al. Diabetic retinopathy in the west of Scotland: its detection and prevalence and the cost-effectiveness of a proposed screening programme. Bull (Edin) 1983;41:318-26.

8 Burns-Cox CJ, Dean Hart JC. Screening of diabetics for retinopathy by ophthalmic opticians. Br Med f 1985;290. 1052-4.

9 Hill RD. Screening for diabetic retinopathy at primary care level. Diabetologia 1981;20:670.

10 Hurwitz BS, Solomonides AE, Wilsher D, Yudkin JS. A diabetic data base and prompting system to improve community care. Diabetic Medicine 1987;4:357.

11 Bron AJ. Screening for treatable diabetic retinopathy. $\mathrm{Br} \mathrm{Med} \mathcal{J}$ 1985;290:1025-6.

12 Herron CA. Screening in diabetes mellitus: report of the Atlanta workshop. Diabetes Care 1979;2:357-62.

\section{Graduated compression and its relation to} venous refilling time

SIR,-The disbelief of Professor A N Nicolaides and his colleagues at St Mary's Hospital (5 December, p 1484), that our "careful studies" (31 October, p 1087) did not agree with their own long term clinical experience requires objective evidence.

We are entirely satisfied that the techniques we used were reproducible, and all the investigations were performed by a single person. There would appear to be a basic scientific flaw in the argument they have put forward, since whatever failing they may claim in the use of photoplethysmography, this flaw must then be equally distributed among all the studies, and, as the technician concerned had no preconceived knowledge of the possible results and was thus effectively blinded, we do not see how these factors could have biased the results.

We have, however, considerably more data than those published in this paper and have confirmed the work by using photoplethysmography with no defect being necessary in the garment, and also with a small group of patients studied by volume refilling using a strain gauge plethysmograph. Our results have been confirmed by the group working at St George's Hospital, who also extended their data to include use of venous pressures. ${ }^{1}$ It is most unfortunate that the extensive studies quoted from St Mary's do not seem to have been published.

We appreciate the potential limitations of our classification and can confirm that all patients included within the deep venous incompetence group had phlebographic evidence of incompetence at popliteal level. One might, however, speculate on the need to attempt a pure separation in the face of equivalent defects in venous function.

The clear statistical significance of the results, albeit in small numbers of patients, to us would confirm the clinical importance of these results. 